\title{
Pneumatic Stabilization of Vehicles
}

\author{
J. Hurtecak \& J. Volf \\ Czech University of Life Sciences Prague, Faculty of Engineering, Prague, Czech Republic
}

\begin{abstract}
The article deals with trends of development in car production and concentrates on car stabilization. It describes the new method of the pneumatic car stabilization as the support ESP method. Let's get to know about trends of development in car production and concentrates on car stabilization. We summarize properties of present systems with their advantages and disadvantages, also describes the new method of the pneumatic car stabilization as the support of ESP method. Presently the calculations were made of real situations by car stabilization that validate this theory.
\end{abstract}

KEYWORDS: car stabilization; inadequate speed; adherence loss; turning; roadway surface; pressured air; ABS; ESP

\section{INTRODUCTION}

Modern cars, trucks and motorbikes as well are today equipped with a lot of active and passive safety components. Among the basic ones is the ABS - anti-lock braking system. It is used in personal cars and lorries and recently motorbikes as well. This anti-lock system was first introduced in 1978 by firms Bosch and Mercedes-Benz as an extra equipment for additional charge at model $\mathrm{S}$ and since then has been widely spread in all models at all car types. Anti-lock braking system is today an obligation without which the car couldn't successfully obtain homologation.

\section{PRESENT STATE OF CAR STABILIZATION}

The ABS has gradually been connected with other systems which make the comfort better and increase the car safety and safety of the other transport participants as well.

These other systems are especially:

- BAS (brake assistant) - recognizes critical situations and enables full braking effect

- ASR (anti-slip regulation) - prevents slipspinning at acceleration and moving off

- EMS reduces rotary inertia until the powered wheels are at the full adhesion

- MSR prevents slip-spinning when braking using the engine

- ESP prevents car slipping
Since these systems keep the vehicle in required direction, they are very important and surely help the car driver. But there are also situations when all these mostly preventive systems cannot help the car because behaviour of people behind the wheel is unpredictable and is also influenced by other drivers who can change behaviour of the driver so that his reaction is not good. What can play an important role is weather. There are situations when on very clean road without snow or ice after the machinery clearing are places with some ice - for example on bridges.

The new method of car stabilization would be a good in these situations and could help the driver and solve a problematic situation more easily an maybe save people's lives.

There exists a new possibility of car stabilization during driving. The system can help to improve safety. Into these critical situations the driver can get either (in first line personal car) by an inadequate speed in turning, or when there is an adhesion loss in turning, e. g. by change of a roadway surface or by both together (Kovanda, J. \& all. 2009).

In present used car stabilization systems work in connection with the ABS. From the pressure sensor of brake fluid the control unit is informed about the pressure in braking system. The sensors measure the pressure that is created by pressing the brake pedal. Then the ABS control unit compares these signals in both ways. The control unit is informed about the actual pressure in brake system by the pressure sensor of the brake fluid. 


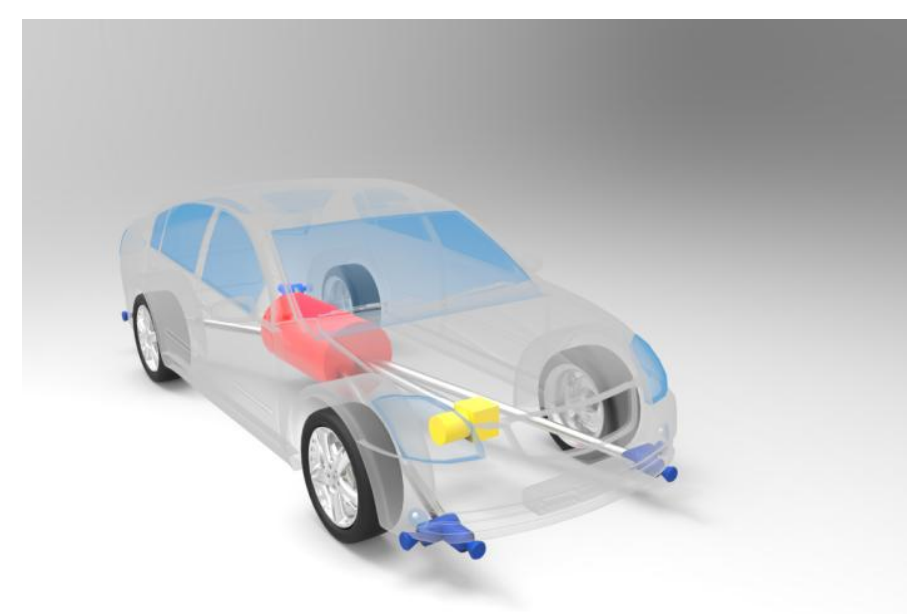

Figure 1. The schematic design of car stabilization components.

The Figure 1-2 show the schematic design of components organization in the car. If the interference is necessary and then the control unit uses the actual value of the brake pressure to the calculation of side forces.

The sensor of the longitudinal vehicle acceleration that is the next part of the system is assembled to a car with drive on all wheels. On cars with drive of only one axletree the system calculates the longitudinal vehicle acceleration from the brake pressure sensor signals, from the wheels revolutions sensors and from the information of the engine control unit.

The sensor of the side acceleration of the vehicle informs about side forces applied on the car. This information is important for calculations of the forces that have to be overcome for staying up the car in the intended way. The sensor read stay if the car doesn't revolve around the vertical axis. The micro mechanic system with the double tuning fork from silicon monocrystal placed on the sensor desk is the basic part of the sensor of the rotary speed. The double tuning fork is created by exciting tuning fork and specific tuning fork.

The sensor of the steer angle is the next part of the car stabilization. This sensor sends partly signal about the steer angle and partly signal about the speed of the steering-wheel turn. Both signals are at first evaluated in the control unit and then sent to the control unit of electromechanical servo control (Cerha, J. 2010). Two absolute magnetic angle sensors are to disposition for the control unit Bosh. These absolute sensors (in contrast to incremental sensors) give the information about the steer angle in the full angles range in every time.

The accelerometers give considerable information part about the car behavior. The accelerometers are the sensors for measurement of static and dynamical acceleration. They are used not only for measurement of eccentric and inertial forces, but for determination a subject position, it's a declination or vibrations, too.
All these car stabilization types use information about a car behavior and about on a car enabled forces to the car keeping in the intended trajectory by the wheels separate braking, eventually by the engine torque changing, eventually by its redistribution to the separate axletree, respectively on the separate wheel.

The adhesive solution is common disadvantage of all these systems.

\section{PNEUMATIC STABILIZATION OF CAR}

New trend in development and some system upgrade to above-mentioned the cohesive security system pneumatic car stabilization can be. In this case it goes about the idea Newton role action and reaction using. The define very pressured air volume will grab form jets which are placed in car body corners near from wheels in the critical moment (Direct Industry. 2013).

The necessary components are compressed-air reservoir compressed air tubes to jets independent jets by wheels quick vents by jets compressed-air reservoir connection to the ESP control unit Humidifiers, J. S. 2013).

The compressor preferentially will use electrical energy obtained by car braking or by ride from hill, the right moment of the compressor run is possible from data of car GPS navigation. It this case is possible use energy recuperation. By this way the ESP control unit can by better prepared to the relevant action and driver can be informed by shining pilot light about impending danger relatively on time.

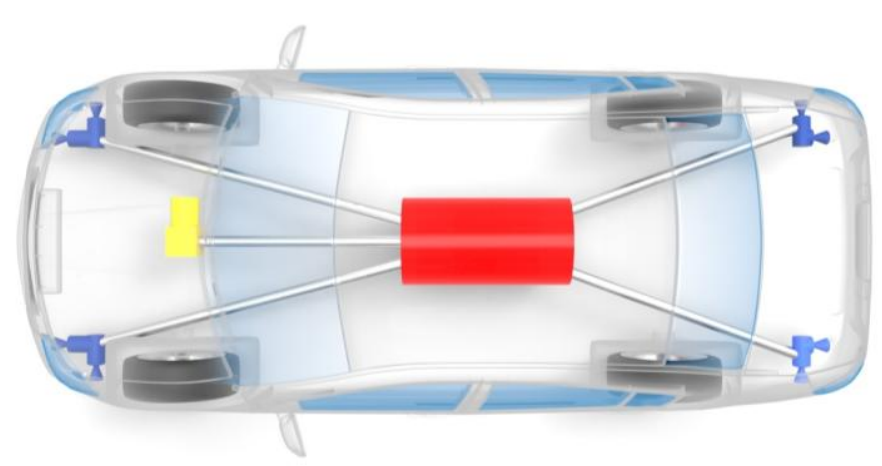

Figure 2. The schematic design of components organization in the car.

By red color the compressed-air reservoir, placed in car centrum of gravity; by yellow color the compressed-air reservoir; by white color compressed air tubes and by blue color the jets in the car body corners. 


\section{CONCLUSION}

We focused on the present stability car trends problems and showed a new possibility by using the pneumatic car stability system and increasing the active car safeness in dangerous and specific situations. Now the question is if and when car manufacturers decide to use the system as a way how to make the car operation safer and better. The systems make cars more complicated in some way and of course more expensive but if we consider massive production, the costs may be less and in comparison with the price of life no costs are high. As for space needed for the technical device, it is not that big problem because it can be placed at the bottom of the car and will not occupy more space than for example the gas reservoir which is used in cars equipped with this invention. The pneumatic car stabilization is the device to help both cars and people anyway.

\section{REFERENCES}

[1] Kovanda, J. \& Ruzicka, T. \& Kepka, M. 2009. Bonding of Structural Parts of Vehicle Bodies and Aspects of Passive Safety. Transactions on Transport Sciences, 2009, Vol. 2, No. 2, pp. 74-85. ISSN: 1802-971X

[2] Cerha, J. 2010. Hydraulické a pneumatické mechnismy I. (in Czech) 2. vydání. Liberec: Technická univerzita $\mathrm{v}$ Liberci. 2010. ISBN 80-7372-560-0.

[3] Direct Industry. 2013. Air eliminator. [online]. [cited 201309-20].

[4] <http://www.directindustry.com/prod/mankenberggmbh/air-eliminators-25111-499369.html>.

[5] Humidifiers, J. S. 2013. JetSpray - the World'sleading air \&wateratomisinghumidifier. [online]. [cited 2013-09-20].

[6] <http://www.jshumidifiers.com/jetspray-the-worldsleading-air-water-atomising-humidifier-436-details/> . 